https://doi.org/10.35219/im.2018.2.03

\title{
TWO METHODS OF ASSESSING THE DISCOMFORT CREATED BY VIBRATION ON A RIVER SHIP
}

\author{
Fiz. Drd. Laurentiu Picu \\ "Dunarea de Jos" University of Galati \\ Engineering and Agronomy Faculty of Brăila
}

\begin{abstract}
The discomfort during the voyages is a subjective reaction of the navigating personnel thus it can be divided in: overall discomfort - only for longitudinal, transverse and vertical accelerations, the total discomfort, rated on a scale of 1 (high discomfort) to 5 (small discomfort) and harmful discomfort - motion sickness due to prolonged low frequency. This paper analyses the comfort for 4 persons who are part of the crew of a river ship on the Danube, depending on the dynamic variables (accelerations measured with the accelerometer). The determinations were made according to ISO 20283-5 (Measurement of vibration on ships). Whole-Body Vibrations characteristic quantities were calculated: timeweighted accelerations, time periods after which the exposure value that triggers the action and the exposure limit value, Sperling's comfort index and Comfort Note. The Comfort Note differs substantially from Sperling's travelling comfort index. If the average of the latter is 2.284829 , that is near an average comfort on a scale of 1 to 5 , the average Comfort Note is 4.16413 (on the same scale) - that is a very poor travel comfort. Given that time-weighted acceleration values are in the range $3-4 \mathrm{~m} / \mathrm{s}^{2}$, with an average of $\sim 3.72 \mathrm{~m} / \mathrm{s}^{2}$ - that is more than twice the limit of discomfort $\left(1.15 \mathrm{~m} / \mathrm{s}^{2}\right)$ - it can be concluded that the assessment of the comfort of the crew members is better done by using the definitions for the Comfort Note than those for calculating the Sperling index for travelling comfort.
\end{abstract}

KEYWORDS: accelerations, exposure value, exposure limit value, Sperling's comfort index, Comfort Note

\section{INTRODUCTION}

Comfort is the totality of the material conditions that ensure a civilized, pleasant, comfortable and hygienic existence (DEX).

A man can feel different degrees of comfort, totally different from what another man feels. To assess comfort, each person must be asked. Regarding the comfort when traveling by a means of locomotion, the subjects refer to a cumulative of variables.

The quality of travel is a person's' reaction to a set of physical conditions inside the means of transport; in the case of travelling by ship, they are (fig. 1): a) dynamic variables - movements that are measured with accelerometers on all 3 axes: lateral, longitudinal and vertical, or in the case of angular movements: roll, pitch and yaw); also, sudden movements (shocks and jolts) are taken into account [1];

b) environmental variables - temperature, pressure, air quality and ventilation, light intensity, noise and vibration;

c) spatial variables - working space and resting area, the quality of the interior facilities;

d) human variables;

e) psychological variables - the usual effects of past and present experience, the emotional effects, etc. 


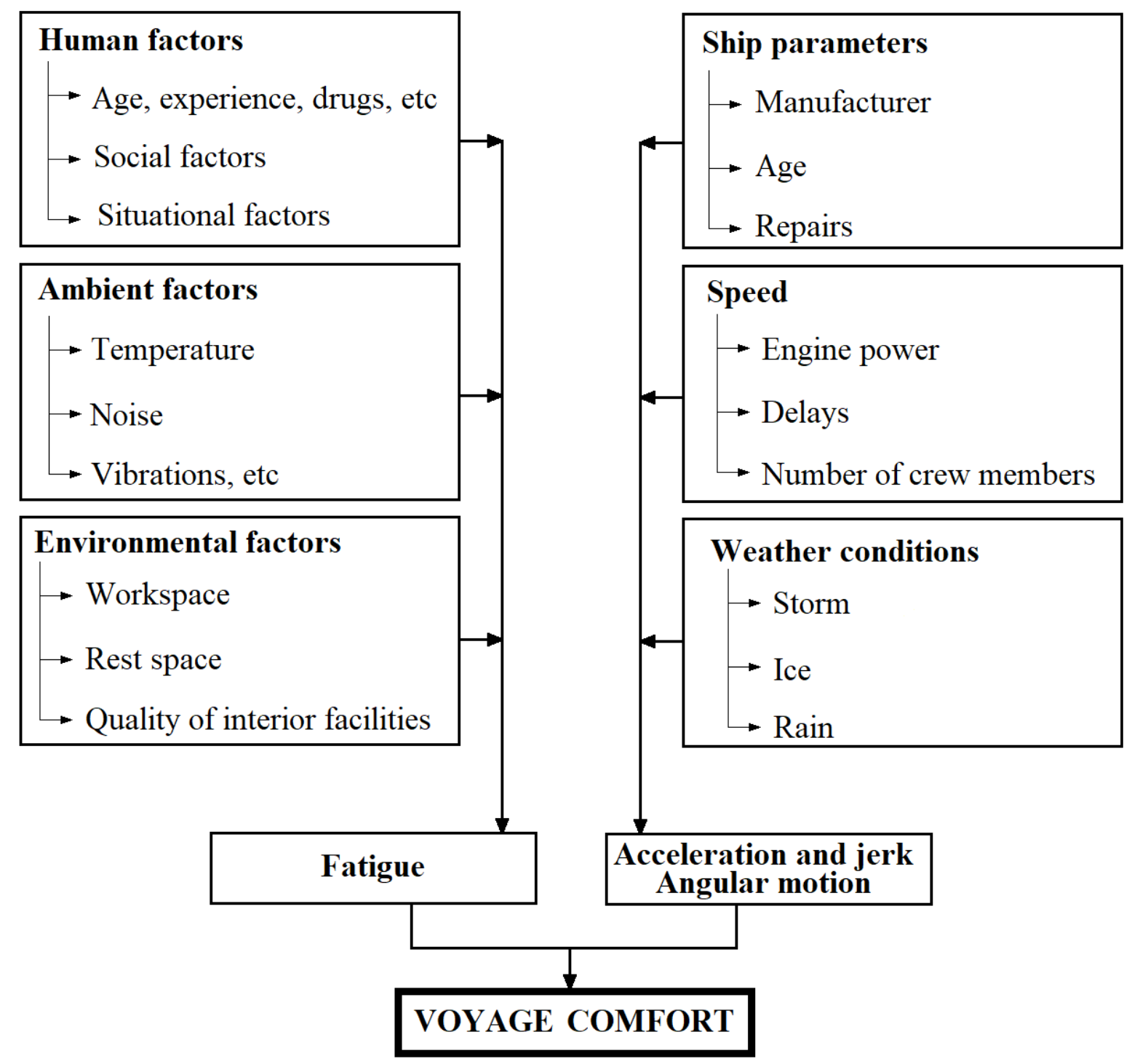

Figure 1. The influence of the different factors on the comfort of the navigating staff during the voyages

The discomfort during the voyages is a subjective reaction of the navigating personnel thus it can be divided in:

1) overall discomfort - only for longitudinal, transverse and vertical accelerations in the range $0.5-80 \mathrm{~Hz}$ (ISO 2631-1). These vertical vibrations $(5-6 \mathrm{~Hz})$ even influences the writing and the spillage of water while drinking $(\approx 4$ $\mathrm{Hz}$ ) [2].

2) the total discomfort, rated on a scale of 1 (high discomfort) to 5 (small discomfort) refers to:

- Walking index discomfort- only for accelerations (longitudinal, lateral and vertical) in a frequency range from $0.5 \mathrm{~Hz}$ to $80 \mathrm{~Hz}$. The higher average values show a low level of comfort when traveling and an increased level of discomfort. Examples of comfort/discomfort scales: Wz [3], Ride
Index, $\mathrm{N}_{\mathrm{MV}}$ [4], evaluation according ISO 2631-1 [5].

- Estimated travel comfort - the subjects rated travel comfort on a 5-point scale from 1 (very good travel comfort) to 5 (very poor travel comfort) [6],

- The discomfort caused by very high horizontal accelerations (jerks and jolts).

3) harmful discomfort - motion sickness due to prolonged low frequency $(<0.5 \mathrm{~Hz})$ transverse and/or angular movements. This type of discomfort leads to dizziness, headache or nausea.

In order to calculate comfort (or discomfort), it is necessary for the acceleration to be weighted by a weighting curve, then to calculate the root mean square acceleration for a period of time (e.g. $1 \mathrm{~min}$ ) or for a length of the route (e.g. $1 \mathrm{~km})$. The weighting curves are shown in fig. 2: those on the lateral and 


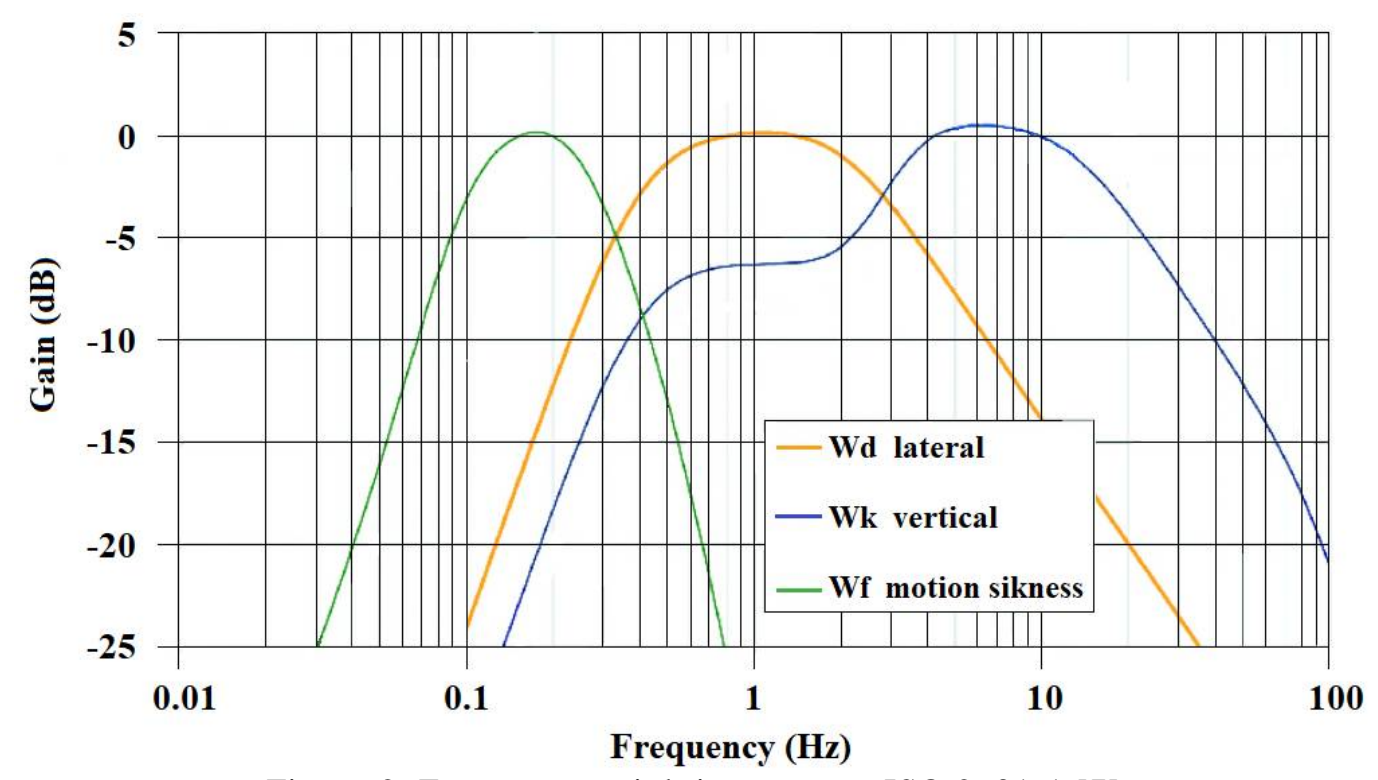

Figure 2. Frequency weightings curves-ISO 2631-1 [7]

longitudinal directions are $\mathrm{Wd}$, and the vertical ones are $\mathrm{Wk}$. Wf curves are related to motion sickness (fig. 2).

\section{MATERIALS AND METHODS}

"Exposure action value and exposure limit value for WBV under the EU 2002/44/EC Physical Agents (Vibration) Directive

- Exposure Action Value. If daily vibration exposure is likely to exceed an $\mathrm{A}(8)$ of 0.5 $\mathrm{m} / \mathrm{s}^{2}$ or a vibration dose value of $9.1 \mathrm{~m} / \mathrm{s}^{1.75}$ action should be taken to reduce exposure to below this value.

- Exposure Limit Value Controls must be put in place to ensure a worker is not exposed under any circumstances to a daily vibration exposure $A(8)$ of more than $1.15 \mathrm{~m} / \mathrm{s}^{2}$ or vibration dose value of $21 \mathrm{~m} / \mathrm{s}^{1.75, "}$ [8].

The vibration of the whole body, under different conditions, was measured on the 3 axes ( $x, y$ and $z$ ) of the centre of the human body. Whole-body vibrations were measured using the $01 \mathrm{~dB}$ NetdB multichannel system, the SEAT-pad triaxial accelerometer and the Piezotronics 356A16 PCB triaxial accelerometer. The axes were oriented in the directions specified in EN 1032. The accelerations were calculated using the factors established by ISO 2631. The calibration of the accelerometers was made with VE-10 Rion.
Whole-body vibrations were measured according to the ISO 2631/1 standard, using the $01 \mathrm{~dB}$ NetdB multichannel system, with the floormounted triaxial SEAT-pad accelerometer.

In all calculations made to determine the degree of discomfort due to vibration, the dimensions of the subject must also be considered. For this, the Body Mass Index (BMI $=\mathrm{m} / \mathrm{h}^{2}$, where $m$ is the mass of the subject and $h$ the height) was calculated for each case (tab. 1).

Table 1. Subjects classification by BMI

\begin{tabular}{|c|c|}
\hline Category & BMI $\left(\mathrm{kg} / \mathrm{m}^{2}\right)$ \\
\hline Severe thinness & $<16,5$ \\
\hline Moderate thinness & $16,5-18,4$ \\
\hline Normal & $18,5-24,9$ \\
\hline Overweight & $25-29,9$ \\
\hline Obese Class I & $30-34,9$ \\
\hline Obese Class II & $35-39,9$ \\
\hline Obese Class III & $>40$ \\
\hline
\end{tabular}

This paper analyses the comfort for 4 persons (tab. 2) who are part of the crew of a river ship on the Danube, depending on the dynamic variables (accelerations measured with the accelerometer). The determinations were made according to ISO 20283-5; 64 experimental determinations were made.

Table 2. Subjects information

\begin{tabular}{|c|c|c|c|c|c|c|c|c|}
\hline Subject & BMI & $\begin{array}{c}\text { Age } \\
\text { (years) }\end{array}$ & Smoker & Drinker* & $\begin{array}{c}\text { Seniority } \\
\text { (years) }\end{array}$ & Diabetes & $\begin{array}{c}\text { Cardio-vascular } \\
\text { problems }\end{array}$ & $\begin{array}{c}\text { Personal } \\
\text { problems }\end{array}$ \\
\hline 1 & 30.4 & 56 & - & - & 25 & $\mathrm{x}$ & - & $\mathrm{x}$ \\
\hline 2 & 28.7 & 58 & Yes & Yes & 34 & - & - & $\mathrm{x}$ \\
\hline 3 & 26,8 & 48 & Yes & Yes & 18 & - & $\mathrm{x}$ & $\mathrm{x}$ \\
\hline 4 & 24,4 & 41 & Yes & - & 20 & - & $\mathrm{x}$ & - \\
\hline
\end{tabular}

*More than 2 glasses of wine/day 
In the first part of the experiments were measured the accelerations on the 3 axes (fig. 3 ).

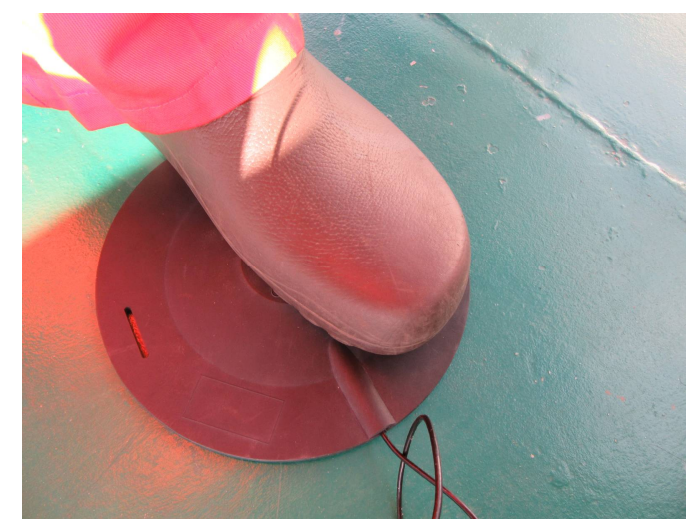

Figure 3. Leg placed on the SEAT-pad triaxial accelerator

The vibration assessment should include measurements of the weighted mean square acceleration (r.m.s.). It is expressed in $\left[\mathrm{m} / \mathrm{s}^{2}\right]$ for translational vibrations and in $\left[\mathrm{rad} / \mathrm{s}^{2}\right]$ for rotational vibrations [5].

With the software...were calculated the time-weighted accelerations.

$$
\mathrm{A}_{\mathrm{w}}=\sqrt{\frac{1}{T} \int_{0}^{T} a_{w}^{2}(t) d t}
$$

where $A_{w}$ is the weighted average acceleration, $\mathrm{a}_{\mathrm{w}}(\mathrm{t})$ time-weighted acceleration and $\mathrm{T}$ measurements duration [s].

Another value that better characterizes the vibrations transmitted to the whole body is the vibration dose. „The VDV is a cumulative value, which increases with measurement duration. It is assessed using the length of time of the measurement and the total time a worker is exposed to the source of vibration per day" [9].

$$
\mathrm{VDV}=\left[\frac{1}{T} \int_{0}^{T}\left[A_{w}(t)\right]^{4} d t\right]^{1 / 4} \quad\left[\mathrm{~m} / \mathrm{s}^{1.75}\right]
$$

Next were calculated the time periods after which the exposure value that triggers the action (EAV) and the exposure limit value (ELV):

$$
\begin{aligned}
& T_{E A V_{A(8)}}=8\left(\frac{0,5}{A_{w}}\right)^{2} \quad[\mathrm{~h}] \\
& T_{E L V_{A(8)}}=8\left(\frac{1,15}{A_{w}}\right)^{2} \quad[\mathrm{~h}]
\end{aligned}
$$

Two other values of interest in the study of the vibrations transmitted to the whole body are: TWA Peak (the highest value of $A_{w}$ determined throughout the measurement) and Raw Peak (the highest value of the vibration measured in the positive/negative direction (on the $\mathrm{Z}$ axis up and down) [10,11].

In order to reduce the fatigue during travel, Sperling's comfort index was defined.

$$
W_{z}=10 \sqrt{\left(\begin{array}{l}
n_{f} \\
\sum W_{i=1}
\end{array} W_{i}^{10}\right.}
$$

where $\mathrm{n}_{\mathrm{f}}$ is the total number of discrete frequencies of the vehicle acceleration response identified by the FFT, and $\mathrm{W}_{\mathrm{zi}}$ is the comfort index corresponding to the $\mathrm{i}$ discrete frequency, given by:

$$
W_{z_{i}}=\sqrt[10]{A_{w}^{3} B\left(f_{i}^{2}\right)^{3}}
$$

where $A_{w}$ is the weighted vibration magnitude r.m.s., iar $\mathrm{B}\left(v_{\mathrm{i}}\right)$ is a weighting factor, given by:

$$
\mathrm{k} \sqrt{\frac{1.911 v^{2}+\left(0.25 v^{2}\right)^{2}}{\left(1-0.277 v^{2}\right)^{2}+\left(1.563 v-0.0368 v^{3}\right)^{2}}}
$$

where $\mathrm{k}=0.737$ for horizontal vibration and 0.588 for vertical vibration [12].

Many of the methods presented so far did not considered the duration of exposure; in this regard, Karakasis et al. [13] defined the Comfort Note $(\mathrm{CN})$ :

$$
\begin{gathered}
\mathrm{CN}=10^{z_{2}}[\mathrm{~h}] \\
\mathrm{Z}_{2}=\frac{-0,06 \mathrm{Z}_{1}^{2}+1,6 \mathrm{Z}_{1}+0,08}{\mathrm{Z}_{1}+4} \\
\mathrm{Z}_{1}=\lg (\mathrm{Aw})
\end{gathered}
$$

where $A_{w}$ is the weighted vibration magnitude r.m.s. [12].

\section{RESULTS AND DISCUSSIONS}

Figure 4 shows the experimental measurements made using the SEAT pad on the 3 axes: $a, a_{y}$ and $a_{z}$. It can be seen that most of the acceleration values on the $\mathrm{x}$ and $\mathrm{y}$ axes are in the range $1-2 \mathrm{~m} / \mathrm{s}^{2}$, while the values on the $\mathrm{z}$ axis are in the range $2-3 \mathrm{~m} / \mathrm{s}^{2}$. 


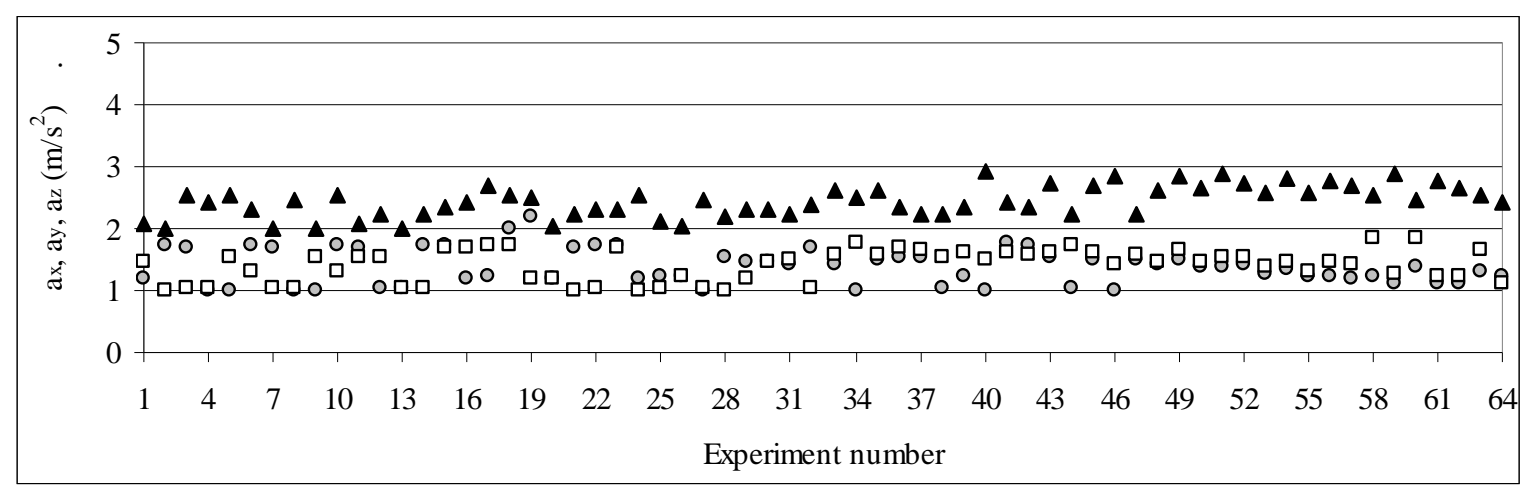

Figure 4 Experimental determinations of accelerations on each axis.

$(\bullet)-\mathrm{a}_{\mathrm{x}} ;(\square)-\mathrm{a}_{\mathrm{y}} ;(\boldsymbol{\Delta})-\mathrm{a}_{\mathrm{z}}$;

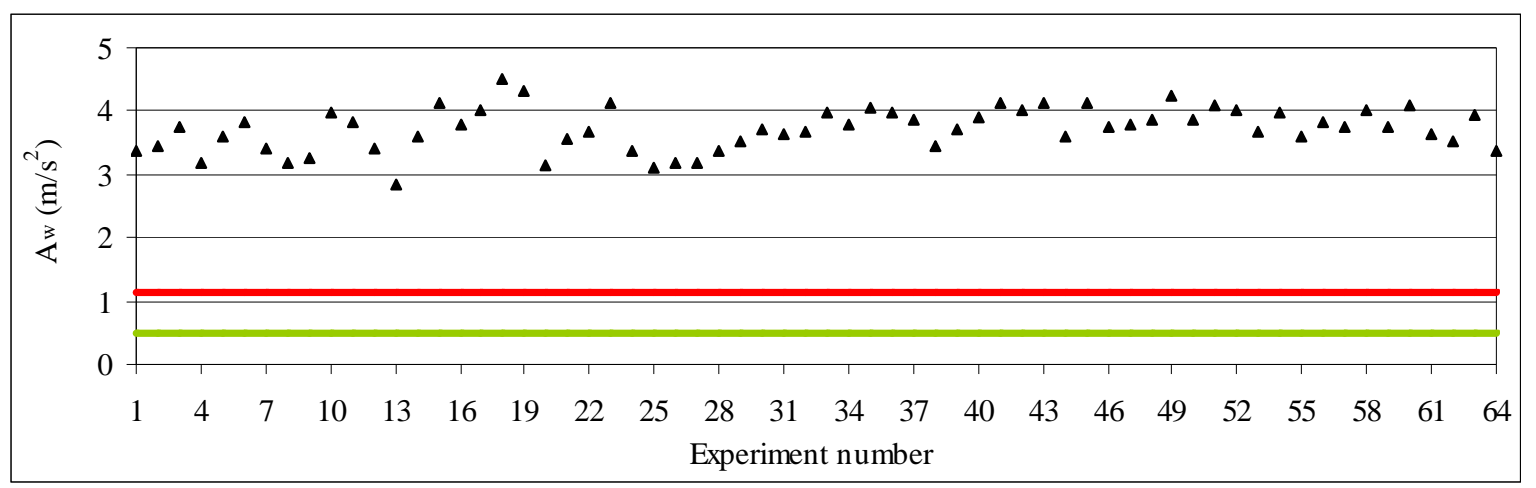

Figure 5. Graphical representation of time-weighted accelerations attention limit (- $)-0.5 \mathrm{~m} / \mathrm{s}^{2}$ and discomfort limit (- $)-1.15 \mathrm{~m} / \mathrm{s}^{2}$, according to the guidelines of the health caution zones [5]

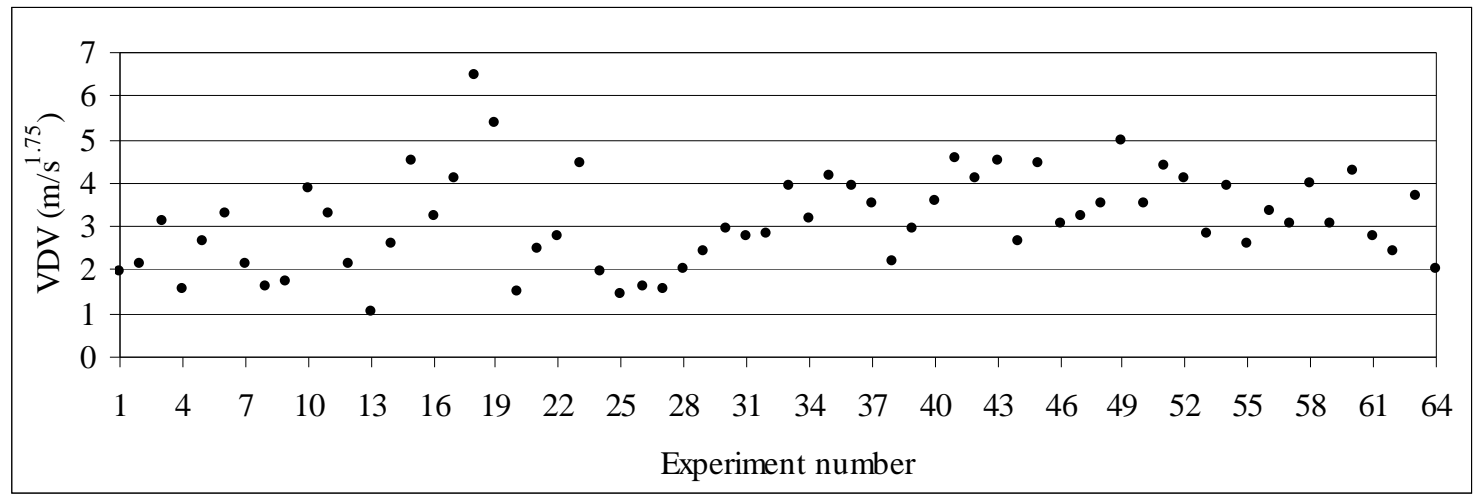

Figure 6. Graphical representation of the vibration dose for each experiment

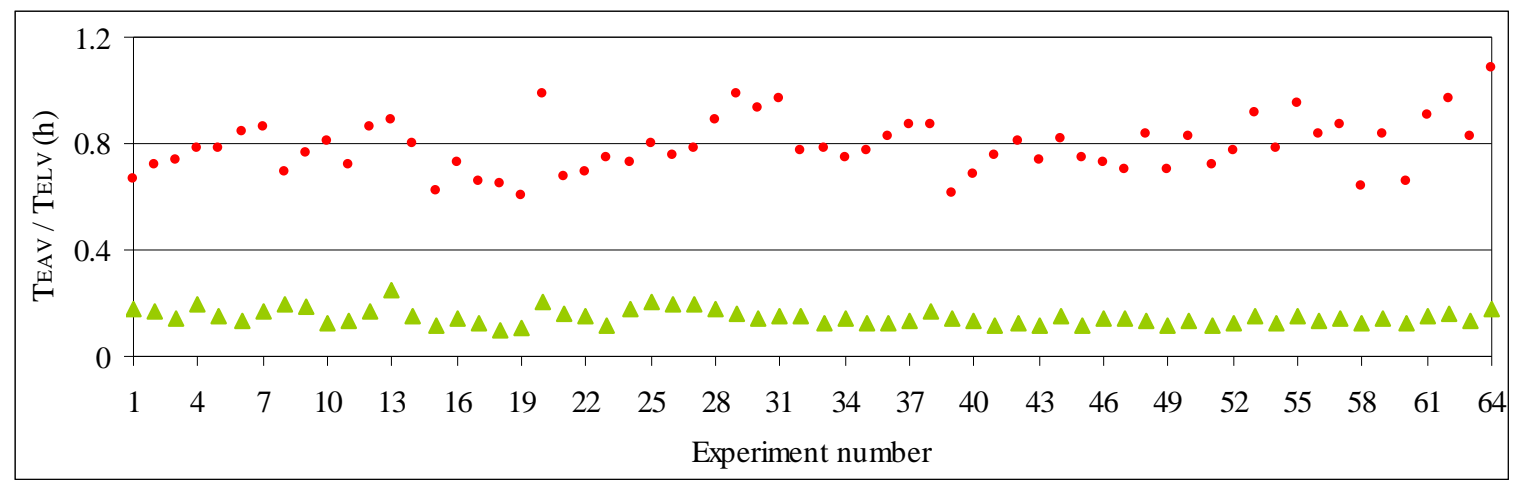

Figure 7. Graphical representation of time periods after which the exposure value that triggers the action $(\mathrm{EAV}-\triangle)$ is reached and the exposure limit value (ELV - •) 
Time-weighted accelerations were calculated (fig. 5) and it is seen that absolutely all the results are above the discomfort limit $\left(1.15 \mathrm{~m} / \mathrm{s}^{2}\right)$ and most of them are in the range of $3-4 \mathrm{~m} / \mathrm{s}^{2}$, with an average of $3.719608 \mathrm{~m} / \mathrm{s}^{2}$.

The value that best characterizes the vibrations transmitted to the whole body is the vibration dose (VDV); it was calculated according to Eq 2. The graphic representation of the VDV is in fig. 6.

Also were graphically represented, the time periods after which the exposure value that triggers the action (EAV) was reached and the exposure limit value (ELV) according to Eqs. 3 and 4 (fig. 7):

In this case, the average $T_{E A V_{A(8)}}=$ $0.14922 \mathrm{~h}=8.953174 \mathrm{~min}$ and average: $T_{E L V_{A(8)}}=$ $0.78937 \mathrm{~h}=47.36229 \mathrm{~min}$

Of interest in the study of vibrations transmitted to the whole body are also:

- the highest value of $A_{w}$ determined throughout the measurement (TWA Peak); in our case this peak was reached during experiment no. 18 and it is $4.51169 \mathrm{~m} / \mathrm{s}^{2}$

- the highest value of vibration measured in the positive / negative direction (on the $\mathrm{Z}$ axis up and down) (Raw Peak); in our case this peak was reached during experiment no. 40 and is $2.923 \mathrm{~m} / \mathrm{s}^{2}$.

In order to calculate the Sperling index for comfort while traveling, Eqs 5, 6 and 7 were used. $B(v)$ was calculated for the 2 cases (horizontally and vertically) for the first frequencies in the one-third octave band: $v=$ 7.875; 15.75 and $31.5 \mathrm{~Hz}$ (fig. 8).

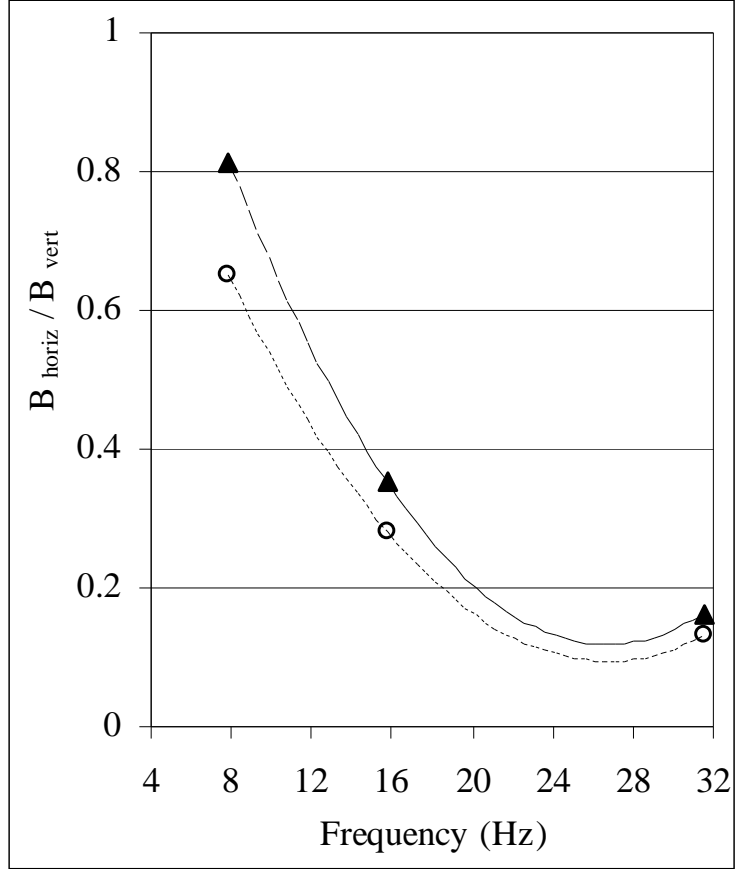

Figure 8. Graphical representation of the $B_{\text {horiz }}$ and $B_{\text {vert }}$ coefficients depending on the

frequency ( $\boldsymbol{\Delta}$ ) - $\mathrm{B}_{\text {horiz }} ;(\mathrm{o})-\mathrm{B}_{\text {vert }}$

Figure 8 shows that the two dependencies are perfectly aligned on 2 parabolas:

$$
\begin{array}{ll}
B_{\text {horiz }}=0.002 \cdot v^{2}-0.1051 \cdot v+1.5197 & \left(R^{2}=1\right) \\
B_{\text {vert }}=0.0016 \cdot v^{2}-0.0838 \cdot v+1.2125 & \left(R^{2}=1\right)
\end{array}
$$

Next were calculated $\mathrm{W}_{\mathrm{zi}}$ for horizontal, respectively vertical, for the 3 frequencies of interest, using Eq. 6 (fig. 9).

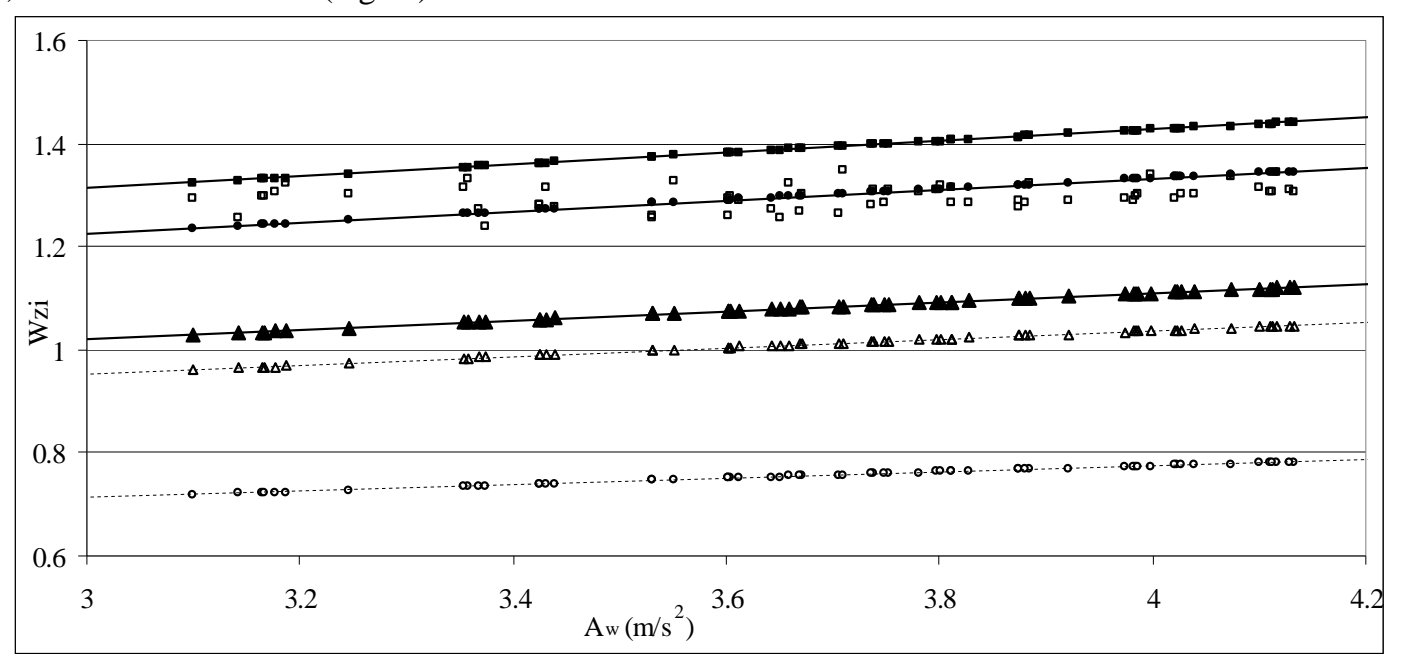

Figure 9. Dependence of the comfort index corresponding to the $i$ discrete frequency depending on the weighted vibration r.m.s.

\begin{tabular}{|c|c|c|c|c|c|c|}
\hline Legend & \multicolumn{3}{|c|}{ Horizontal } & \multicolumn{3}{c|}{ Vertical } \\
\hline $\mathrm{v}(\mathrm{Hz})$ & 7.875 & 15.75 & 31.5 & 7.875 & 15.75 & 31.5 \\
\hline $\mathrm{W}_{\mathrm{zi}}$ & $\mathrm{W}_{\mathrm{z} 1}$ & $\mathrm{~W}_{\mathrm{z} 2}$ & $\mathrm{~W}_{\mathrm{z} 3}$ & $\mathrm{~W}_{\mathrm{z} 4}$ & $\mathrm{~W}_{\mathrm{z} 5}$ & $\mathrm{~W}_{\mathrm{z} 6}$ \\
\hline Symbol & $\square$ & $\mathbf{\Delta}$ & $\bullet$ & $\square$ & $\Delta$ & $\mathrm{O}$ \\
\hline
\end{tabular}




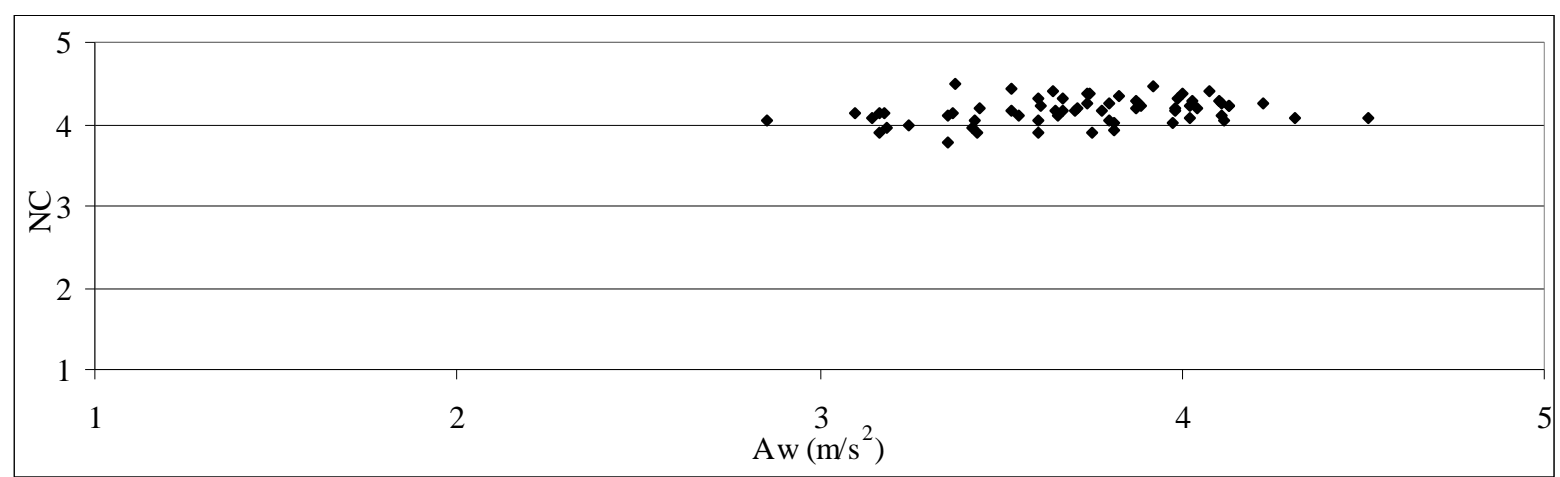

Figure 10. The dependence of the $\mathrm{CN}$ depending on the amplitude of the acceleration response

In fig. 9, the comfort indices depending on the amplitudes of the acceleration responses is of the type $\mathrm{W}_{\mathrm{zi}}=\mathrm{C} \cdot \mathrm{A}_{\mathrm{w}}+\mathrm{D}$ (straight), except in case 4 (vertical, $v=7.875 \mathrm{~Hz}$ ), in which case the curve could not be drawn.

$$
\begin{gathered}
W_{1}=0.114 \cdot A_{w}+0.9701 \quad\left(R^{2}=0.9831\right) \\
W_{2}=0.0887 \cdot A_{w}+0.7547\left(R^{2}=0.9739\right) \\
W_{3}=0.1065 \cdot A_{w}+0.906 \quad\left(R^{2}=0.9983\right) \\
W_{4}=\text { the curve could } \text { not be drawn } \\
W_{5}=0.0829 \cdot A_{w}+0.7052 \quad\left(R^{2}=0.9898\right) \\
W_{6}=0.0619 \cdot A_{w}+0.5267 \quad\left(R^{2}=0.9974\right)
\end{gathered}
$$

Then, Sperling's travelling comfort index, defined by Eq. 5 will be: $\mathrm{W}_{\mathrm{z}}=2.284829$.

According to the assessment of the estimated comfort, it is noted that in this case it is about an average comfort (on a scale from 1 to 5$)$.

Regarding the comfort note, it was calculated with Eqs. 8, 9 and 10. The results are shown in fig. 10.

The average values obtained for $\mathrm{CN}$ are is 4.16413. If from these points the extremes are eliminated - experiment $13 \quad$ (2.853028, 4.033511) and experiments 18 and 19 (4.51169, 4.07926 and 4.311334, 4.079785) - a very condensed distribution will be obtained. The $\mathrm{CN}$ belongs to the interval (3.77325169 and 4.48168451). In this case, the average is 4.167462 , which is practically equal to the one obtained in the first case.

In this case, the $\mathrm{CN}$ is very close to a very poor travel comfort (which is rated at 5).

\section{CONCLUSIONS}

Following the experiments it was found that the minimum value of time-weighted acceleration is $1.035247 \mathrm{~m} / \mathrm{s}^{2}$; the maximum value is $4.51169 \mathrm{~m} / \mathrm{s}^{2}$, higher by $74,51 \%$ than the discomfort limit and by $88,91 \%$ than the attention limit. Given that the size that best characterizes the vibrations transmitted to the whole body is the vibration dose, it is calculated that the minimum value of VDV is $1.035247 \mathrm{~m} / \mathrm{s}^{1.75}$, and the maximum value is $6.474067 \mathrm{~m} / \mathrm{s}^{1.75}$, with an average of 3.133562 $\mathrm{m} / \mathrm{s}^{1.75}$, that is lower than the provisions of the EU Directive 2002/44/EC (as opposed to acceleration values).

The CN differs substantially from Sperling's travelling comfort index. If the average of the latter is 2.284829 , that is near an average comfort on a scale of 1 to 5 , the average $\mathrm{CN}$ is 4.16413 (on the same scale) that is a very poor travel comfort. Given that time-weighted acceleration values are in the range $3-4 \mathrm{~m} / \mathrm{s}^{2}$, with an average of $\sim 3.72 \mathrm{~m} / \mathrm{s}^{2}-$ that is more than twice the limit of discomfort $\left(1.15 \mathrm{~m} / \mathrm{s}^{2}\right)$ - it can be concluded that the assessment of the comfort of the crew members is better done by using the definitions for the $\mathrm{CN}$ than those for calculating the Sperling index for travelling comfort.

\section{REFERENCES}

[1] ISO 20283-5:2016 Mechanical vibration - Measurement of vibration on ships - Part 5: Guidelines for measurement, evaluation and reporting of vibration with regard to habitability on passenger and merchant ships, December.

[2] Corbridge C., \& Griffin M. J. (1991). Effects of vertical vibration on passenger activities: writing and drinking. Ergonomics, 34(10), pp. 1313-1332.

[3] Sperling E., and Betzhold C. (1956). Beitrag zur beurteilung des fahrkomforts in schienenfahrzeugen, Vol. 80. Dresden, Germany: Glasers Annalen, 314-320.

[4] Förstberg J., Ride comfort and motion sickness in tilting trains - Human responses to motion environments in train experiment and simulator experiments, Doctoral thesis, 2000, Available at:

www.diva-portal.org/smash/get/diva2:8728/FULLTEXT01.pdf

[5] ISO 2631-1:1997 Mechanical vibration and shock - Evaluation of human exposure to whole-body vibration - Part 1: General requirements

[6] Förstberg J., (2000). Motion-related comfort levels in tilting trains: Human responses and motion environment in a train experiment (SJ X2000). KTH-TRITA-FKT Report 2000:27. Stockholm: KTH

[7] Jiang Y., Chen B.K., Thompson C., A comparison study of ride comfort indices between Sperling's method and EN 12299, International Journal of Rail Transportation, 7(4) 2019, pp 279-296

[8] Directive 2002/44/EC of the European Parliament and of the Council, of 25 June 2002 on the minimum health and safety 
requirements regarding the exposure of workers to the risksarising from physical agents (vibration)

[9] Safe Work Australia, Guide to measuring and assessing workplace exposure to whole-body vibration,

https://www.safeworkaustralia.gov.au/system/files/documents/1703

/guidetomeasuringassessingwholebodyvibration.pdf

[10] Valášek M., Pelikán J., Úlehla J., Vaculín, O., Steinbauer

P., Experimental Verification of Correlation between Objective and

Subjective Evaluation of Passenger Car Vibration Comfort,

BULLETIN OF APPLIED MECHANICS 4(15), 99-101 (2008)

https://www.researchgate.net/profile/Pavel_Steinbauer/publication/ 26850767_Experimental_Verification_of_Correlation_between_O bjective_and_Subjective_Evaluation_of_Passenger_Car_Vibration _Comfort/links/5548a2530cf2b0cf7aceef56.pdf
[11] Mortadha Graa, Mohamed Nejlaoui, Ajmi Houidi, Zouhaier Affi, Lotfi Romdhane, Modeling and Simulation for Vertical Rail Vehicle Dynamic Vibration with Comfort Evaluation, 17-19 December, Sousse, Tunisia,

https://link.springer.com/book/10.1007/978-3-319-14532-7

[12] Picu Ana, Modelarea biomecanică neliniară a dinamicii corpului uman sub acţiunea vibraţiilor transmise, $\mathrm{PhD}$ Thesis, 2010

[13] Karakasis K, Skarlatos D and Zakinthinos T., 2005, A factorial analysis for the determination of an optimal train speed with a desired ride comfort Applied Acoustics 66(10) pp. 11211134 